\title{
Diet and Life Style Modification be able to Reduce the Risk of Coronary Heart Diseases
}

\author{
Nessa $\mathrm{A}^{1}$, Uddin $\mathrm{MM}^{2}$, Ferdousi $\mathrm{S}^{3}$, Hussain $\mathrm{MA}^{4}$ \\ J Bangladesh Soc Physiol. 2006 Dec;(1):40-41. \\ For author affiliations, see end of text.
}

\section{To The Editor}

I $\mathrm{n}$ the developed societies the major cause of death and premature disability is atherosclerosis. It is also an emerging health problem in developing countries like Bangladesh. Atherosclerosis -this extremely widespread disease predisposes to myocardial infarction, cerebral thrombosis, ischemic gangrene of the extremities and other illness. Myocardial infarction is a very common cause of death due to sequele of atherosclerosis. 1,2

In the UK (population 59 million) 1 in 3 in men and 1 in 4 in women die from CHD (coronary heart disease), an estimated 330000 people have myocardial infarct each year and approximately1.3 million people have angina ${ }^{2}$.

Although great advances have been made in prevention and treatment of CHD through drug therapies and procedures, diet and lifestyle modification remain the foundation of clinical intervention for prevention. Unfortunately, above mention are commonly neglected, to the detriment of patients.

The rationality of this scientific writing is to promote the healthy behaviors and increases public awareness of blood cholesterol level, there by reduce population- wide lipid levels and reduce the need for drug therapy. In affluent societies dietary cholesterol is derived mainly from egg yolk (the richest source), dairy products and red meat; the daily intake is about11.5 to 2.0 mmol (600 to $800 \mathrm{mg}$ ). Inhibition of hepatic cholesterol synthesis, by suppression of the enzyme HMG CoA reductase, may not prevent intracellular accumulation of lipid if dietary intake is excessive ${ }^{3,5}$.

J Bangladesh Soc Physiol. 2006 Dec;(1):40-41
Dyslipidemia plays a vital role in atherosclerotic cardiovascular diseases. Dyslipidemia is a disorder of lipid metabolism including lipoprotein over production or deficiency. $2,3,5,6$

Low HDL-cholesterol is a strong independent predictor of coronary heart disease (CHD). HDL-Cholesterol has been identified as a lipoprotein that protects against atherosclerosis and its levels are inversely proportional to the risk for developing ischemic coronary heart disease. HDL- $\mathrm{C}$ physiologically removes excess cholesterol from arterial walls and transports it to the liver, where it is re-metabolized and excreted in the form of biliary acids. ${ }^{3-6}$

LDL-cholesterol is a strong risk factor for atherosclerosis. When serum LDL-cholesterol exceeds physiological limit it then taken up by macrophages and some other cells. When the macrophages become overloaded with oxidized LDL, they become "foam cells" that are seen in early atherosclerotic lesions of the arterial walls. ${ }^{5-6}$

Research studies suggest that the protector effect of "Good" cholesterol (HDL-C) is stronger than the atherogenic effect of "Bad" cholesterol (LDLC). ${ }^{3,4,6}$ Elevated TG frequently associated with low HDL and increased 'small dense' LDL. ${ }^{1,5}$ LDL cholesterol and triglyceride measurements are useful for guiding the treatment, but do not improve CHD risk prediction better than measurement of total and HDL cholesterol only. 5, 8, 9

The National Cholesterol Education Program Adult Treatment Panel III (NCEP-ATP III) recommends beginning screening of all adults at 
age 20, regardless of cardiovascular risk profile. 3 Lifestyle changes can favorably affect total cholesterol, HDL cholesterol, LDL cholesterol and triglyceride levels. A reduction on total cholesterol by 1 percent may decrease a person's risk of developing coronary heart disease by 2 percent. $3,4,7,9$

Diet and preventive life style measures - that help to control lipid level 1, 3, 4, 7, 10

- Aim for a healthy body weight - Attain and maintain normal body weight.

- Consume an overall healthy diet-Follow a diet containing less than $25 \%$-35\%of calories from fat, less than $7 \%$ of calories from saturated fat, and fewer than $200 \mathrm{mg}$ of cholesterol per day.

- $\quad$ Emphasize a plant based diet.

- Consume a diet rich in vegetable and fruits.

- Choose whole-grain, High-fiber foods.

- Minimize your intake of beverages and foods with added sugars.

- If one consumes alcohol, consume no more than 1 to 2 alcoholic beverages per day.

- Avoid use of and exposure to all forms of tobacco products.

- Be physically active. Exercise aerobically for at least 30 minutes on most and preferably all days of the week.

Regardless of the presence of preexisting CHD, patients who adopt these habits will have healthier lipid profiles, placing them in lower risk strata for cardiovascular events.

Preventive management of dyslipidemia can markedly alter lipid levels thereby decrease cardiovascular morbidity and mortality.

\section{Author Affiliations}

*1. Dr Akhtarun Nessa, Assistant Professor, (c.c) Physiology Department of Physiology, Mymensingh Medical College, Mymensingh, Bangladesh, Email:

J Bangladesh Soc Physiol. 2006 Dec;(1):40-41 nessa_akhtarun@yahoo.com

2. Dr M Murshed Uddin, Associate Professor (cc), Department of Physiology, Mymensingh Medical College, Mymensingh, Bangladesh

3. Dr Sultana Ferdousi, Assistant Professor of Physiology, BSMMU, Shahbag, Dhaka, Bangladesh

4. Dr MAnowar Hussain, Consultant ENTD, Kishoregonj Adhunik Sadar Hospital, Kishoregonj, Bangladesh

* for correspondence

\section{References}

1. Kopin LA, Pearson TA. Dyslipidemia. Ann Intern Med. 2007;147(5):ITC9-2-ITC9-16.

2. Bloomfield P, Brodbury, GrubbNR, Newby DE. Cardiovascular Disease. In: Boon NA, Colledge NR, Walker BR, Hunter JA, editors. Davidson's Principles \& Practice of Medicine. Churchill Livingstone: Elsevier Limited; 2006. p.519-646.

3. Executive Summary of the Third Report of the National Cholesterol Education Program(NCEP)Expert Panel on Detection, Evaluation, and Treatment of High Blood Cholesterol in Adults(Adult Treatment Panel III).JAMA. May 16 2001;285(19)2486-2497.

4. Screening for Lipid Disorders in Adult U.S. Preventive Services Task Force. Rockville MD; 2001.Accessed at www.ahrq.gov/clinic/uspstf/uspscholhtm on11 July 2007

5. Mayne PD. Clinical Chemistry in Diagnosis and Treatment. $6^{\text {th }}$ ed. India: B.I publication pvt Ltd;1994

6. Ganong WF. Review of Medical Physiology. $22^{\text {nd }}$ ed. Singapore : McGraw Hill; 2005.

7. Kreisberg RA, Oberman A. Medical management of Hyperlipedemia/ Dyslipidemia. J Clin Endocrinol Metab. June 2003; 88(6): 2445-2461.

8. Lichenstein AH, Appel LJ, Brands M et al. Diet \& Lifestyle recommendations revision 2006. A scientific statement from the American Heart Association Nutrition Committee.Circulation.2006;114:82-96

9. Garber AM, Browner WS. Guidelines for using serum cholesterol, high-density lipoprotein cholesterol, and triglyceride levels as screening tests for preventing coronary heart disease in adults. Ann Intern Med.1996 March 1; 124(5):516-17.

10. Van Dam RM, Rimma EB, Willett WC, Stampfer MJ, Hu FB. Dietary patterns and risk type 2 diabetes mellitus in U.S men. Ann InternMed.2002; 136:201-209 